\title{
OPINIONS REGARDING THE EFFICIENCY OF THE METHODICAL PROCEDURES FOR DEVELOPING THE COORDINATING CAPACITY OF THE FIGHTER'S BODY
}

\author{
Robert STĂNCIULESCU*, Cristian Sorin STĂNCIULESCU** \\ *"Nicolae Bălcescu" Land Forces Academy, Sibiu, Romania \\ **"Lucian Blaga" University of Sibiu, Romania \\ rstanciulescu@armyacademy.ro,stanciulescu_cristian87@yahoo.com
}

\begin{abstract}
The military actions carried out throughout time strongly highlight the special importance that the level of motor capacity development has in the training of the fighter. A great number of research studies have underlined the effects of a regular participation in complex training programs that ensure an adequate level of development of the components of this training category. Therefore the identification of the optimal scientific methods for the development of the components of physical capacity is a priority in the training system. The paper points to the methodical aspects related to maximizing a basic component of the motor capacity of the fighter's body, namely the coordination capacity which involves identifying the best methods and procedures for maximizing the effects of the body's dexterity, mobility and suppleness.
\end{abstract}

Keywords: action, fighter, capacity, mobility, suppleness

\section{Introduction}

In the general sense, any methodology deals with a certain side, a certain aspect, a certain moment of the instructiveeducational process and is thus placed in the system of pedagogical sciences that take into account the problems of training and education The definition can be taken into account only if the didactics is conceived as the set of pedagogical preoccupations in the area of school life proper, which is particularized in phenomena specific to each type of activity. Most of the times, however, the methodology defined in this way is reduced to a deductive process, which is limited to applying the principles and rules of general didactics, to teaching an educational subject matter, without taking into account the educational implications specific to the process [1].
The methodology of physical activities represents that branch of the science of physical education which expresses, in a generalized form, certain realities of the learning process. It arose from the need to generalize and optimize the experience gained in the field of physical activities. In this ample process it is certainly necessary to utilize the information related to the aspects specific to the physical development, to the particular motor and psychic development, as well as the information derived from the laws that manage the efficiency of teaching activities, definitely having as a final objective the obtaining of exceptional results. Starting from the idea of exploiting the results of the relationship between the objectives of the field, the particular physical properties and the system of action, the methodology of 
physical activities beneficially contributes to organizing the training process, taking into account the following variables:

- particularities of age and sex;

- conditions for carrying out the activity;

- the existing material base;

- specific of the institution;

- sports discipline;

- existing native qualities;

- environmental conditions;

- other specific aspects which contribute to obtaining the results.

As a scientific discipline, the methodology of physical activities tries to highlight their essence and seeks to explain the causes of the didactic phenomena and the relationship between the activity of trainers and trainees in relation to the results obtained. The methodology provides information related to certain norms of the didactic activity, as well as to modern forms and methods of action and ensures the combination of older but efficient techniques with them. In this way the methodology of physical activities appears as an active theory that has a practical purpose.

\section{Physical capacity, support generating efficiency in combat actions}

The training, maintenance and development of the general and specific movement capacity of the body is an essential objective, perhaps the most important of the physical activities, and the study of the methods to be used for obtaining the established performance is a priority for the specialists in the field.

The level of development of the body's coordination qualities, which include dexterity, mobility and suppleness is essential for achieving performance in the field of physical education and sports, and contributes in particular to the successful fulfillment of the professional activity of the fighter. We can appreciate that their development really influences the activity and improvement of the main functions of the body, increasing the capacity for effort, developing the spirit of observation, imagination, inventive thinking, steadfastness, perseverance or courage, as well as the shaping, strengthening and enhancing the basic motor and utilitarianapplicative skills and abilities demanded by the modern battlefield [2].

It is extremely important to know that the development of the body's coordination capacity is based on efforts, which must be well-directed and rigorously designed, as their scope is quite complex at the level of the body.

Thus, in addition to the muscular or osteoarticular effort, the body also exerts efforts of the nervous system, the obtaining of high performance representing not only the tasks of physical activity but also the tasks pertaining to the moral-volitional field such as will, courage or self-confidence.As previously mentioned, the energy resources mobilized in order to develop the coordination capacity are channeled in a general effort of the body which aims, among other things, at the development of motor qualities. The dosing of the effort necessary to achieve the objectives is done with great attention both by the performers and by the specialized staff, taking into account some variables, the most important of which are the essential characteristics of the effort, namely volume, intensity and complexity. It is extremely important to know the fact that during motor actions muscle contractions are the result of chemical processes, and their performance involves a high consumption of oxygen. The body certainly has the ability to provide the oxygen needed to restore the energy substrate and, depending on how much it can provide over time, two types of effort can be differentiated: the predominantly aerobic efforts, which are characterized by an instantaneous recovery of the energy substrate, meaning that during the motor act the oxygen supply necessary for the body's recovery is also achieved. Here we can speak of a low-intensity effort. The predominantly anaerobic efforts are characterized by a high and very high intensity. The body fails to provide the oxygen needed to restore the energy 
substrate, this restoration being done over time, so for recovery the body needs a longer time to ensure the necessary oxygen supply. These are aspects that must be taken into account to a very large extent in the implementation of the methods specific to the development of the body's coordination capacity.

\section{The methodology of developing the coordinative capacity}

Most motor actions are related to the body's capacity for effort. Through the working methods, the coordinative capacity, formed by dexterity, mobility and suppleness, is positively or negatively influenced, it being in direct proportionality with the level of the physical effort capacity of the organism.

\subsection{Methodical procedures of developing the skill}

As we have previously presented, the skill, through its forms of manifestation, is represented by balance, spatio-temporal orientation, amplitude or muscle relaxation. Most specialists consider it extremely important that the skill should be at optimal parameters as it favors the efficient execution of all motor and utilitarianapplicative skills specific to various motor actions, as well as the development of other motor qualities of the athlete's body.

The methodical procedures for developing this skill are numerous. In Table No. 1 we will present the main general methodical procedures and their specific exercises that are indicated in the development of the specific skill of the fighter's body:

Table no. 1-Methodical procedures of developing the skill

\begin{tabular}{|c|c|c|}
\hline No. & Methodical procedure & Exercises \\
\hline 1. & $\begin{array}{l}\text { Using unusual starting positions for } \\
\text { doing the physical exercises }\end{array}$ & $\begin{array}{l}\text { - Jumping over certain obstacles from different } \\
\text { positions } \\
\text { - Start with your back towards the running direction } \\
\text { from various positions (squatting, lying down, sitting, } \\
\text { etc.) }\end{array}$ \\
\hline 2. & $\begin{array}{l}\text { Performing the exercises with the } \\
\text { awkward segment (arm, leg, etc.) }\end{array}$ & $\begin{array}{l}\text { - Throwing objects (balls, disc, weights, exercise } \\
\text { grenades, etc.) with the hand opposite to the preferred } \\
\text { one } \\
\text { - Self-defense with reverse guard or from different } \\
\text { positions } \\
\text { - Performing (basic) gymnastic exercises in the mirror } \\
\text { or vice versa as demonstrated by the instructor, etc. }\end{array}$ \\
\hline 3. & $\begin{array}{l}\text { Changing the tempo and the } \\
\text { execution system }\end{array}$ & $\begin{array}{l}\text { - Running in various tempos and with running variants } \\
\text { (with the knees up, with the legs swinging backwards, } \\
\text { forwards, etc.). } \\
\text { - Carrying out the attacks, the opponent or the obstacles } \\
\text { in various tempo or with the gradual acceleration until } \\
\text { the completion phase }\end{array}$ \\
\hline 4. & $\begin{array}{l}\text { Limiting the space where the } \\
\text { exercise takes place }\end{array}$ & $\begin{array}{l}\text { - Game structures, preparatory and dynamic games on } \\
\text { small pitches (football "mules", basketball on a basket } \\
\text { on a small space, etc.) }\end{array}$ \\
\hline 5. & $\begin{array}{l}\text { Carrying out the technical } \\
\text { procedures and their chaining with } \\
\text { restrictions }\end{array}$ & $\begin{array}{l}\text { - Exercises from games without dribbling or with a } \\
\text { single dribble } \\
\text { - Exercises to correct the technique }\end{array}$ \\
\hline 6. & Changing the execution procedures & - Jumping over obstacles by various means \\
\hline
\end{tabular}


According to some authors, the most efficient methodological procedures would be:

- the execution of exercises in different conditions;

- performing the exercises by changing the execution procedures;

- performing the exercises in difficult conditions;

- changing the speed of execution of the exercises.

In all situations it is necessary to take into account the fact that learning the exercises should be done according to the principles: from simple to complex, from easy to difficult, from known to unknown and through their development and execution at a high speed.

\subsection{Methodical procedures of developing mobility and suppleness}

The specific means of developing mobility and suppleness are chosen according to the objective pursued, taking into account the needs of technical training, the degree of general physical training and the native anatomophysiological properties that a certain individual possesses. There are a large number of types of exercises used for fulfilling the objectives. Adrian Dragnea makes the following classification in the sports training [3]:

- active exercises;

- passive exercises;

- dynamic exercises;

- static and relaxation exercises;

- combined exercises.

We further present the description of the specific exercises utilized in developing mobility and suppleness:

- free exercises such as: bendings, downturns, rotations, flexions, extensions, swings performed in series of 3 to 5 rhythmic consecutive repetitions. The balancing exercises are performed in the form of consecutive arches (8-10 times). This type of exercise is very effective because it uses the inertia of movement, which ultimately leads to an increase in mobility;

- exercises with weights (with medicinal balls, small objects such as dumbbells, bats, etc.) that, on the one hand, capitalize well on the effect of the inertia of movement, and, on the other hand, accentuate the stretching of tense muscles;

- combined exercises - half dynamic and half static - are applied in the situation in which the development of the elasticity of some muscle groups is pursued, which limits the movement and strength of the antagonists. These exercises require an indispensable warm-up for intensifying the blood circulation in the muscles subjected to stretch, otherwise articular or muscular trauma can rise.

The word stretching comes from "stretch", which means "stretch" in English [4]. It is a system of exercises that involves maintaining a segment in a certain position for a short period of seconds in order to gradually stretch a muscle and prepare it for a specific effort which it will be subjected to.Among the methods and techniques used in stretching we can mention the following exercises:

- arching and passive maintenance which consist in performing repeated, unabrupted contractions of the agonist muscles, in order to quickly stretch the antagonistic muscles

- stretching and passive maintenance performed with the help of a partner. The stretching movement of the trained limb is slow, soft and passive until it reaches an extreme position, in which a certain embarrassment is felt; this is maintained for 6 seconds, an interval in which the respective muscle (agonist) is subjected to an isometric contraction;

- active proprioceptive neuromuscular training in which the movement is performed for 6 active seconds, being followed by a maximum isometric contraction against the opposite resistance of the antagonistic muscles

- the relaxation technique consists in performing a slow passive stretching, with 
the help of the partner, until it reaches an extreme position, which is maintained for 1 minute, during which time the performer relaxes mentally through self-control.

Last but not least, it should be noted that the way in which the objectives for development are met depends to a large extent on the professional qualities of the teachers, coaches and instructors who manage the training activity.

\section{Conclusions}

Ensuring higher indices in the development of motor capacity is an essential condition of efficiency in specific activities. The modalities of developing the motor capacity are adapted according to the specifics of the situation and the objectives pursued, but they also involve general activities used in all motor activities. Most specialists consider the motor capacity to be formed by certain elements, among which the coordinative capacity of the organism. The level of development of the coordinative capacity represents an essential condition of the development of the basic motor qualities, of the consolidation and improvement of the motor skills required on the battlefield, having special influences on the conditioning of the physical and mental health of the fighter's body.

\section{References List}

[1] Rizescu, A., Stănciulescu, R., Didactica specialităţii militare, "Nicolae Bălcescu" Publishing House, Sibiu, 2011.

[2] Stănciulescu, R, Capacitatea motrică, fundamente teoretice și metodice, ,"Nicolae Bălcescu" Publishing House, Sibiu, 2017.

[3] Dragnea, A., Teodorescu, Mate, S., Teoria sportului, Bucharest, Fest Publishing House, 2002.

[4] Tudor, V., Evaluarea în educaţia fizică şcolară, Printech Publishing House, 2001. 